\title{
Assessment of quality of life in patients after COVID-19 infection: A questionnaire-based observational study
}

\author{
Kiran Raj Hanumantha ${ }^{1}$, Pooja Naik², Lavanya Varma ${ }^{3}$, Manoj Varma ${ }^{4}$, Shruthi Manipal, \\ Pavitra Sampath ${ }^{6}$ \\ ${ }^{1}$ Assistant Professor, Department of Pediatrics, Srinivas Institute of Medical Sciences and Research Centre, Mukka, \\ Mangaluru, Karnataka, India, ${ }^{2}$ Senior Lecturer, Department of Oral Pathology and Microbiology, Srinivas Institute of \\ Dental Sciences, Mukka, Mangaluru, Karnataka, India, ${ }^{3}$ Professor and Head, Department of Conservative Dentistry \\ and Endodontics, Srinivas Institute of Dental Sciences, Mukka, Mangaluru, Karnataka, India, ${ }^{4}$ Professor and Head, \\ Department of Prosthodontics, Crown and Bridge and Implantology, Srinivas Institute of Dental Sciences, Mukka, \\ Mangaluru, Karnataka, India, ${ }^{5}$ Reader, Department of Oral Medicine and Radiology, Srinivas Institute of Dental \\ Sciences, Mukka, Mangaluru, Karnataka, India, ${ }^{6}$ Reader, Department of Conservative Dentistry and Endodontics, \\ Srinivas Institute of Dental Sciences, Mukka, Mangaluru, Karnataka, India
}

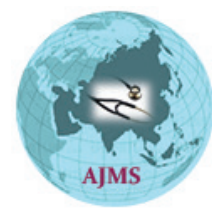

A B S TR A C T

Background: By the end of 2019, the world has witnessed a pandemic of COVID-19 caused by novel coronavirus and is referred to as SARS-CoV-2. Aims and Objectives: The purpose of our research was to show how the COVID-19 pandemic has affected patient`s quality of life after infection with the virus post recovery. Materials and Methods: It was a questionnaire based cross sectional study. Study tool included a reliability checked selfmade questionnaire with 30 questions. It was disseminated through mobile and web-based social media platforms to recovered COVID-19 patients hospitalized at centre, in and around Surathkal. Sample collection was done between September 2020 to December 2020 for about 3 months duration with a total of 550 recovered patients. We found significant stress with increasing age, which was more among males and housewives. Data analyzed by the descriptive statistics association. Results: Out of 550 recovered patients, with 314 (57.1\%) of them being males. The average age was 41.02 years (SD) (16.86). Gender $(p=0.017)$, occupation $(p=0.0002)$, and age $(p=0.001)$ were found to be related to stress levels. Age $(p=0.001)$, occupation $(p=0.001)$, and gender $(p=0.002)$ were found to be related to feelings of isolation. The majority took all precautions, such as social distancing and disinfectant use. Conclusions: Significant increase in stress with increasing age, which was more among males and housewives. Reduced quality of life in males and elderly patients of covid-19 infection predominantly because of psychological discomfort, but family and friends played a major role as coping mechanisms.
http://nepjol.info/index.php/AJMS DOI: 10.3126/ajms.v12i8.37649 E-ISSN: 2091-0576 P-ISSN: 2467-9100

Copyright (c) 2021 Asian Journal of Medical Sciences

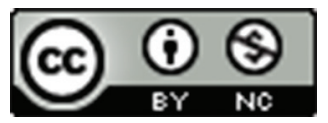

This work is licensed under a Creative Commons Attribution-NonCommercial 4.0 International License.

Keywords: COVID-19; Pandemics; Quality of life; Quarantine; Social media

\section{INTRODUCTION}

Coronavirus disease 2019 (COVID-19) is caused by Severe acute respiratory syndrome coronavirus 2 (SARSCoV-2) a viral pandemic which the globe has witnessed on a never-before-seen scale, which has spread quickly round the world started by the end of 2019 at Wuhan, China ${ }^{1}$ pushing a large portion of the population into quarantine or lockdown. The present pandemic COVID-19 virus has globally resulted in 179 million confirmed cases and 3.8 million deaths as per WHO on $23^{\text {rd }}$ June $2021 .^{2}$ The virus is often spread quickly from one individual to another through the droplets of the respiratory tract formed during coughing and sneezing. It's considered to be most infectious when individuals are symptomatic, in spite of the fact that transmission could be conceivable 
before symptoms appear in contracted individuals. Time from contracting the virus and becoming symptomatic is usually between 2-14 days, five days being the average. Commonest clinical symptoms of COVID-19 include fever, coughing, sneezing, difficulty in breathing, lethargy, headache, myalgia, conjunctivitis. Complications include pharyngitis, pneumonia, acute respiratory distress syndrome. ${ }^{3}$ Hence, distinguishing the disease from other respiratory illnesses becomes challenging., ${ }^{4,5}$

Evidence suggests in addition to the common acute respiratory symptoms (such as cough, dyspnea and fever), COVID-19 patients have been shown to have signs and symptoms of multi-organ dysfunction which can further set hurdles in medical management and have a negative impact on COVID-19 patient's clinical outcomes. In humans SARS-CoV-2 is thought to enter cells through the cell receptor angiotensin-converting enzyme 2 (ACE2). ${ }^{6}$ The ACE2 receptor is found in the gastrointestinal (GI) tract, lungs, liver, kidneys, endothelial cells of the vascular system, and smooth muscle cells of arteries in higher concentrations. ${ }^{7}$ As a result, all of those organs and systems with higher ACE2 receptor expression may be possible SARS-CoV-2 infection targets. ${ }^{8}$

Many researches including Centers for Disease Control and Prevention (CDC) have shown that risk of serious illness and mortality increases with age. Adults that are both aged and having poor medical background are at a higher risk of infection. If infected with the coronavirus, people with cardiovascular and pulmonary diseases, including both elderly people and younger adults, have a higher chance of becoming critically ill. In people who do not have comorbid conditions, the mortality rate is around $1 \%{ }^{9}$ Reverse transcription polymerase chain reaction (RT-PCR) taken from a throat swab or nasopharyngeal is a higher quality diagnostic tool. Coronavirus infection can also be detected by the evaluation of symptoms, a detailed clinical examination, the assessment of risk factors and a chest CT scan which shows pneumonia like characteristic features. ${ }^{10,11}$

Quality of life (QOL) measures became an important and sometimes required as a part of health outcomes appraisal. Measurement of QOL on population provides a consequential way to verify the health care impact when cure isn't possible. It implies value supported subjective functioning as compared with personal expectations and is defined by subjective experiences, states and perceptions. This COVID-19 infection features a remarkable effect not just on physical health, but also on psychological state and overall quality of life. ${ }^{12}$ This has an effect on the entire population, including both people who are healthy and those who are considered vulnerable. The primary goal of this research was to see how the Covid-19 infection affects the quality of life of recovered patients. ${ }^{13}$ The primary objective of our study was to present how the Covid-19 pandemic has impacted the quality of life of patients who have been recovered from infection with Covid-19.

\section{MATERIALS AND METHODS}

The present questionnaire based cross-sectional study was conducted among recovered patients of COVID-19 infection who fulfilled the inclusion and exclusion criteria.

\section{Participants}

COVID-19 recovered patients who were hospitalized, home isolated and both hospitalized - home isolated formed the study group. The present study was conducted on hospitalized patients of Srinivas Institute of Medical Sciences and Research Centre and patients in and around Surathkal, Mangaluru.

\section{Sample size}

The required sample size for the study was calculated by taking into consideration a power of $80 \%$, and CI $-95 \%$ with $5 \%$ data error, final sample size obtained was 550 .

\section{Inclusion criteria}

- All the recovered COVID-19 patients aged above 18 years

- Patients under home isolation following COVID -19 infection

- Patients hospitalized and treated for COVID -19.

- All the patients willing to participate in the study.

\section{Exclusion criteria}

- Recovered patients below 18 years

- Patients of COVID -19 following infection those who died.

- $\quad$ Patients not infected with COVID -19.

\section{Questionnaire development}

The questionnaire consisted of 30 questions which included parameters like socio-demographic, (5) symptomatology of COVID-19, (1) functional limitation, (2) psychological discomfort, (1) psychological disability, (1) social disability, (2) handicap, (2) patients support, (2) medication and support. A 5-point Likert scale was used to grade the questionnaire. All patients' responses were coded as follows: $0=$ strongly disagree, $1=$ disagree, $2=$ neither agree nor disagree, $3=$ agree, $4=$ strongly agree. The questions were derived from a variety of common national and international standards that were readily available at the time of writing. Any doubts regarding the questionnaire were clarified by the investigator. 


\section{Questionnaire reliability}

A semi-structured questionnaire was formed and extracted from Google forms and exported to Microsoft Excel after testing the inter-rater reliability of the questionnaire among 20 study subjects (excluded from study results) using Cohen's kappa statistic measurement, value was ranged between (0.72) moderate to (1.0) almost perfect level of agreement among 30 questions.

\section{Data collection}

Study was conducted with clearance from the Institutional Ethics Committee (IRB approval) while confirming the standards of the Declaration of Helsinki and its subsequent revisions. After obtaining the informed consent from the recovered patients, the questionnaire was circulated by means of Google form through the web and mobile based social networks like Whats-app, email. Our target population included the Covid-19 recovered patients localized to, in and around Surathkal and Mangalore who were either hospitalized, home isolated or both. The data were collected through web-based means and telephonic conversation among the study participants obtained through a snowball sampling method over a period of 3 months from September 2020 to December 2020.

\section{Statistical analysis}

Data was compiled, entered in Microsoft Excel sheet by using SPSS version 23 and analyzed by descriptive statistics association, Chi-square test. $\mathrm{P}<0.05$ was considered statistically significant.

\section{RESULTS}

Out of 550 patients, the majority 314 (57.1\%) were males and $236(42.9 \%)$ were females. The mean age (SD) was 41.02 years (16.86) and out of 550 patients $239(43.5 \%)$ patients were aged above 40 years and $311(56.5 \%)$ patients were aged between 18 to 40 years.

The study consisted of a majority who tested positive during the month of September (33.5\%) followed by August (28.9\%). This could be due to increased awareness about the disease and also due to increased testing. Majority infected were professionals 103(18.7\%).

In 550 patients, 391(28.9\%) patients had undergone RTPCR and 159 (71.1\%) had undergone Rapid Antigen Test as a diagnostic test for Covid-19. Around 294(53.5\%) patients were home isolated and 256(46.5\%) patients were hospitalized in Covid care centers. In the present sample, $149(27.1 \%)$ patients were suffering from comorbid conditions such as diabetes, hypertension, chronic bronchitis, renal diseases, paralysis, hypothyroidism, myasthenia gravis. Regarding symptoms related to Covid-19 out of 550 recovered patients, 398(72.4\%) patients had fever, $306(55.6 \%)$ had cough and sore throat, 332(60.4\%) had headache and body ache, 262(47.6\%) had complains of loss of smell and taste sensation (Figure 1).

The percentage distribution of $\mathrm{ABO}$ blood group in 550 patients was $21(38.5 \%), 147(26.8 \%), 59(10.7 \%)$ and $132(24 \%)$ for $\mathrm{A}, \mathrm{B}, \mathrm{AB}$ and $\mathrm{O}$ respectively.

Out of 550 patients, $410(74.5 \%)$ patients had taken Zinc, Vitamin D3 and Vitamin C supplements. 110(20\%) patients out of 550 patients had taken immunity boosters/AYUSH treatment. 353(63.3\%) patients had discomfort while carrying out daily routine activities. 338(61.4\%) patients agreed that their life seemed to be less satisfying during Covid-19 infection. 276(50.2\%) patients were embarrassed when they tested positive for Covid-19. 360(65.5\%) patients agreed that they were unable to perform routine physical activity. One hundred ninety eight (36\%) patients were felt financially burdened during hospitalization and home isolation. Out of 550 patients $430(78.2 \%)$ patients were bothered about non-availability of single standard medication and vaccination for Covid-19. 438(79.6\%) patients out of 550 patients were stressed about no complete cure for Covid-19 infection.

Gender wise comparison of stress level.

There was a significant association of stress levels and gender $(p=0.017)$ (Table 1$)$, age $(p=<0.001)$ and occupation $(\mathrm{p}=0.0002)$.

There was significant association seen between feelings of isolation and age $(p=<0.001)$ (Table 2), occupation $(p=<0.001)$ and gender $(p=0.002)$. With increasing age and among males the feeling of isolation was found to be more. Among different occupations, feelings were seen more among housewives and retired people.

Decreased life satisfaction was seen to be associated with occupation $(p=<0.001)$, gender $(p=0.002)$ and age

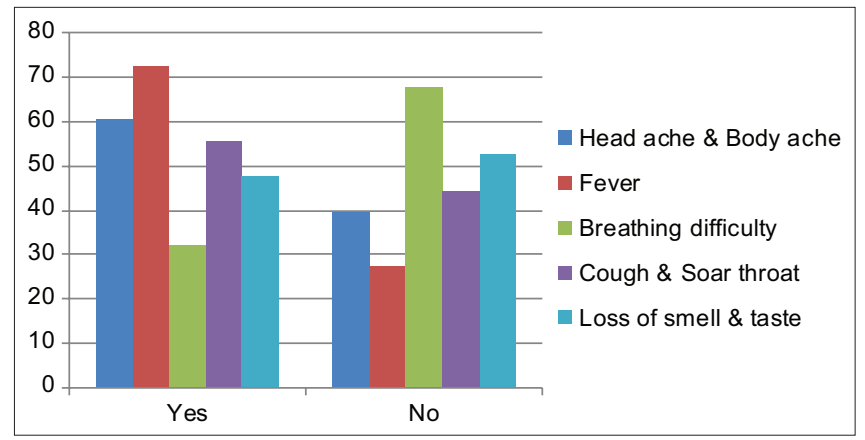

Figure 1: Distribution of patients based on symptoms of COVID-19 
$(\mathrm{p}=<0.001)$. Dissatisfaction was more with increasing age and males and mostly among retired people and housewives.

Even though there was stress among patients of COVID, there was satisfaction about the support level given by the family members and relatives during COVID-19 infection. The association was significant for occupation $(\mathrm{p}=<0.001)$ (Table 3$)$, age $(p=0.025)$, while there was no association between support and concern shown by family members and relatives $(p=0.099)$ for gender both males and females equally felt that support of family and relatives were satisfied.

The association was significant for support by friends and colleagues for age $(p=0.045)$ (Table 4), occupation $(p=<0.001)$ and gender $(p=0.004)$. Among the patients, males and professionals and office staff and age groups between 21-30 and 31-40 years were more satisfied with friends and work colleagues than others.

In our study $318(57.8 \%)$ patients showed persistent symptoms potentially correlated with COVID-19. Patients reported dyspnea on exertion $162(29.4 \%)$, fatigue/ weakness $103(18.7 \%)$, myalgia $32(5.8 \%)$, and arthralgia $21(3.8 \%)$. Two-hundred thirty two $(42.2 \%)$ patients did not have persistent symptoms.

The level of precaution like social distancing, wearing masks and use of hand sanitization was followed by mostly all and hence no association was seen for precaution and age $(p=0.248)$, occupation $(p=0.095)$ and gender $(p=0.091)$.

Table 1: Distribution of patients based on stress levels and gender. (Psychological discomfort)

\begin{tabular}{lccc}
\hline & Females & Males & Total \\
\hline Completely disagree & $7(3.0)$ & $23(7.3)$ & $30(5.5)$ \\
Disagree & $52(22.0)$ & $52(16.6)$ & $104(18.9)$ \\
Neutral & $27(11.4)$ & $56(17.8)$ & $83(15.1)$ \\
Agree & $90(38.1)$ & $119(37.9)$ & $209(38.0)$ \\
Completely agree & $60(25.4)$ & $64(20.4)$ & $124(22.5)$ \\
Total & $236(100)$ & $314(100)$ & $550(100)$ \\
\hline \multicolumn{2}{l}{ Values are presented as number $(\%),{ }^{*} \mathrm{p}=0.017$} & &
\end{tabular}

\section{DISCUSSION}

Studies have reported higher rates of anxiety, depression, substance abuse, poor life satisfaction and suicide during pandemics. NIMHANS gives guidelines to assess colleagues which involve active listening, managing own feelings and questions to assess mental health issues. They also gave arrangements to workspace, enhancing support by family compared to the general population. ${ }^{14}$

The study by Li et al., ${ }^{1}$ had majority males in their study similar to the current study. Suggesting predominance of COVID -19 among males. The study by Chen et al., had a mean age of $55.5 \pm 13.1$ years while in our study it was lower and was 41.02 years. The study by Chen similar to our study had majority male patients. COVID-19 infection is more common in the elderly, according to studies, but the majority of the participants in our sample were under the age of 40 . The study conducted by Xu et al., ${ }^{5}$ in their study had a median age of 41 years.

Study by Chen et al., ${ }^{4}$ had the majority of symptoms of cough and fever followed by shortness of breath, this is similar to the current study where the majority had fever and cough, symptoms of shortness of breath were not seen initially. Similar findings were reported by Xu et al., ${ }^{5}$ and Chen et al. ${ }^{4}$ The study had the majority who were selfemployed while in our study it was professionals.

Centers for Disease Control and Prevention found persisted symptoms in recovered patients of covid-19 infection commonly included fatigue, fever, cough, myalgia, headache, chest pain, dyspnea, depression, arthralgia, cognitive impairment and palpitations, similarly in our study we found dyspnea on exertion 162(29.4\%), fatigue/ weakness $103(18.7 \%)$, myalgia $32(5.8 \%)$, and arthralgia $21(3.8 \%)$. In contrast $232(42.2 \%)$ patients did not have persistent symptoms. ${ }^{15}$

Study done by Chen et al., ${ }^{16}$ found significant physical and psychological impairment with poor HRQoL in Chinese Covid-19 at one month of patient follow-up. Study suggested prospective monitoring is required for

Table 2: Association of feeling of isolation and age among the patients. (Psychological discomfort)

\begin{tabular}{lccccccc}
\hline & \multicolumn{9}{c}{ Age group } & \multicolumn{1}{c}{ Total } \\
\cline { 2 - 7 } & $\mathbf{5} \mathbf{2 0}$ & $\mathbf{2 1 - 3 0}$ & $\mathbf{3 1 - 4 0}$ & $\mathbf{4 1 - 5 0}$ & $\mathbf{5 1 - 6 0}$ & $>\mathbf{6 0}$ & \\
\hline Completely disagree & $0(0)$ & $10(5.6)$ & $7(6)$ & $0(0)$ & $1(1.6)$ & $1(1.1)$ & $19(3.5)$ \\
Disagree & $4(25)$ & $27(15.2)$ & $15(12.8)$ & $22(24.7)$ & $8(12.7)$ & $4(4.6)$ & $80(14.5)$ \\
Neutral & $3(18.8)$ & $41(23)$ & $15(12.8)$ & $11(12.4)$ & $8(12.7)$ & $5(5.7)$ & $83(15.1)$ \\
Agree & $5(31.3)$ & $78(43.8)$ & $62(53)$ & $36(40.4)$ & $33(52.4)$ & $42(48.3)$ & $256(46.5)$ \\
Completely agree & $4(25)$ & $22(12.4)$ & $18(15.4)$ & $20(22.5)$ & $13(20.6)$ & $35(40.2)$ & $112(20.4)$ \\
Total & $16(100)$ & $178(100)$ & $117(100)$ & $89(100)$ & $63(100)$ & $87(100)$ & $550(100)$ \\
\hline Values are presented as number $(\%), * * * p<0.001$ & & & & & &
\end{tabular}

Values are presented as number $(\%), * * * p<0.001$ 


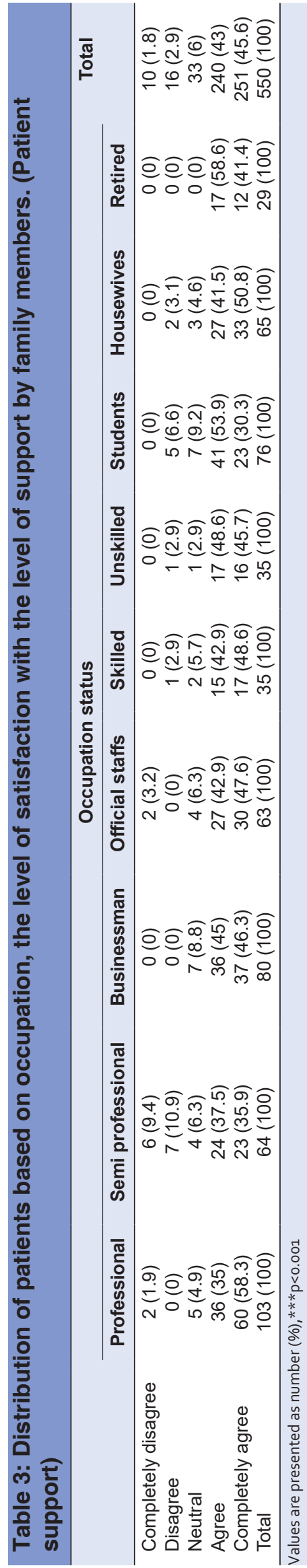

Covid-19 patients so as to completely know the enduring impact of COVID-19, in addition to informing rapid and competent interventions to lessen suffering. In the present study out of 550 patients, 353(63.3\%) patients had (functional limitation) discomfort while carrying out daily routine activities. $338(61.4 \%)$ patients agreed that their life seemed to be less satisfying during Covid-19 infection (handicap). Two hundred seventy six (50.2\%) patients were embarrassed when they tested positive for Covid-19 (psychological disability). Three hundred sixty (65.5\%) patients agreed that they were unable to perform routine physical activity (handicap).

The literature shows that the respiratory viral infection chances will be reduced with supplementation of zinc, vitamin $\mathrm{D}$ and vitamin $\mathrm{C}$. As a result, in the event of COVID-19 pandemic, supplementing with these nutrients could be beneficial because of their availability, safety and cost effectiveness to deal with the increased need for these nutrients just in case of virus contact, to enhance immune responses and to reduce the risk of significant viral infection progression and prognosis. ${ }^{17}$ In the present study $74.5 \%$ of patients had taken vitamin C, Vitamin D and zinc supplements with the minimum days of hospitalization and faster recovery.

In patients with COVID-19, the proportion of type A blood group involvement was significantly higher than in the general population, according to a Wuhan study. The proportion of patients with COVID-19 who had blood group $\mathrm{O}$ was slightly lower. According to the findings, blood group $\mathrm{A}$ and blood group $\mathrm{O}$ have a substantially higher risk of COVID-19 infection than non-A and non-O groups, respectively. The studies have also shown that blood group $\mathrm{O}$ is less vulnerable to COVID 19, American association of hematology have found blood groups $\mathrm{A}$ or $\mathrm{AB}$ to have more severe COVID -19 disease. In the present study also the majority of them belonged to blood group A. ${ }^{18}$

Study by Schofield et al., ${ }^{19}$ found that during times of stress and uncertainty, the family environment provided by parents is a protective factor. Similarly in the current study also family and friends played a major role as a coping mechanism. Cobham et al., ${ }^{20}$ discovered signs of parenting patterns and coping measures impacting children's postdisaster mental health in their research.

According to a study by Sahoo et al., ${ }^{21}$ patients those who are tested positive for Covid-19 infection but are only mildly symptomatic or asymptomatic can access the complete experience of COVID-19 infection, which includes remaining in isolation wards, to be extremely stressful. Adjustable coping mechanisms like simple cognitive 


\begin{tabular}{|c|c|c|c|c|c|c|c|}
\hline & \multicolumn{6}{|c|}{ Age group } & \multirow[t]{2}{*}{ Total } \\
\hline & $\leq \mathbf{2 0}$ & $21-30$ & $31-40$ & $41-50$ & $51-60$ & $>60$ & \\
\hline Completely disagree & $0(0)$ & $0(0)$ & $2(1.7)$ & $0(0)$ & $0(0)$ & $0(0)$ & $2(0.4)$ \\
\hline Disagree & $0(0)$ & $3(1.7)$ & $8(6.8)$ & $3(3.4)$ & $5(7.9)$ & $1(1.1)$ & $20(3.6)$ \\
\hline Neutral & $1(6.3)$ & $21(11.8)$ & $12(10.3)$ & $10(11.2)$ & $2(3.2)$ & $6(6.9)$ & $52(9.5)$ \\
\hline Agree & $7(43.8)$ & $85(47.8)$ & $43(36.8)$ & $44(49.4)$ & $35(55.6)$ & $35(40.2)$ & $249(45.3)$ \\
\hline Completely agree & $8(50)$ & $69(38.8)$ & $52(44.4)$ & $32(36)$ & $21(33.3)$ & $45(51.7)$ & $227(41.3)$ \\
\hline Total & $16(100)$ & $178(100)$ & $117(100)$ & $89(100)$ & $63(100)$ & $87(100)$ & $550(100)$ \\
\hline
\end{tabular}

Values are presented as number (\%), * $\mathrm{p}=0.045$

processes and praying to God, connecting with family and friends, and working with psychological health providers can also help to minimize anxiety levels. Approximately two-fifths of patients experience psychiatric morbidity, even with clinical assistance.

\section{CONCLUSION}

The current study observed increased stress with increasing age, which was more among males and housewives. Majority had taken all the precautionary measures like social distancing and using sanitizers before and after infection.

There was significant stress which led to the decrease in the quality of life, but family and friends played a major role as coping mechanisms and increasing awareness through health education. Precautions and information regarding improving quality of life through coping mechanisms should be addressed and explained to the patients as and when diagnosed with the disease. Health education to the family should be given as it helps in faster recovery. There are very few studies which showed the importance of family as a coping mechanism. Further similar studies should be conducted with the larger sample size to see an effect of the disease on quality of life.

\section{LIMITATIONS OF THE STUDY}

The study had smaller sample size, with no comparator group. This study did not differentiate between the critically ill and patients with relatively mild disease. Study population did not comprise children and larger sample size which should be investigated further in future studies.

\section{ABBREVIATIONS}

Coronavirus disease 2019 (COVID-19), Severe acute respiratory syndrome coronavirus 2 (SARS-CoV-2), angiotensin - converting enzyme 2 (ACE2), Reverse transcription polymerase chain reaction (RT - PCR),
Quality of life (QOL), Centers for Disease Control and Prevention (CDC), Health related quality of life (HRQoL).

\section{REFERENCES}

1. Li Q, Guan X, Wu P, Wang X, Zhou L, Tong $Y$ et al. Early Transmission Dynamics in Wuhan, China, of Novel CoronavirusInfected Pneumonia. New England Journal of Medicine. 2020; 382(13):1199-1207.

https://doi.org/10.1056/NEJMoa2001316

2. WHO Coronavirus (COVID-19) Dashboard [Internet]. Covid19. who.int. 2021 [cited 24 April 2021]. Available from: https:// covid19.who.int

3. Wiersinga W, Rhodes A, Cheng A, Peacock $S$ and Prescott $H$. Pathophysiology, Transmission, Diagnosis, and Treatment of Coronavirus Disease 2019 (COVID-19). JAMA. 2020; 324(8):782.

https://doi.org/10.1001/jama.2020.12839

4. Chen N, Zhou M, Dong X, Qu J, Gong F, Han Y, et al. Epidemiological and clinical characteristics of 99 cases of 2019 novel coronavirus pneumonia in Wuhan, China: a descriptive study. The Lancet. 2020; 395(10223):507-513.

https://doi.org/10.1016/S0140-6736(20)30211-7

5. Xu X, Wu X, Jiang X, Xu K, Ying L, Ma C, et al. Clinical findings in a group of patients infected with the 2019 novel coronavirus (SARS-Cov-2) outside of Wuhan, China: retrospective case series. BMJ. 2020; m606.

https://doi.org/10.1136/bmj.m606

6. Zhou P, Yang X, Wang X, Hu B, Zhang L, Zhang W, et al. A pneumonia outbreak associated with a new coronavirus of probable bat origin. Nature. 2020; 579(7798):270-273. https://doi.org/10.1038/s41586-020-2012-7

7. Santos R, Sampaio W, Alzamora A, Motta-Santos D, Alenina N, Bader $M$, et al. The ACE2/Angiotensin-(1-7)/MAS Axis of the Renin-Angiotensin System: Focus on Angiotensin-(1-7). Physiological Reviews. 2018; 98(1):505-553.

https://doi.org/10.1152/physrev.00023.2016

8. Ding $\mathrm{Y}$, Wang H, Shen H, Li Z, Geng J, Han H, et al. The clinical pathology of severe acute respiratory syndrome (SARS): a report from China. The Journal of Pathology. 2003; 200(3):282-289. https://doi.org/10.1002/path.1440

9. Koma W, Neuman T, Claxton G, Rae M, Kates J and Michaud J. How Many Adults Are at Risk of Serious Illness If Infected with Coronavirus? Updated Data [Internet]. Files.kff.org. March 2020 [cited 1 March 2021]. Available from: http://files.kff.org/ attachment/Data-Note-How-Many-Adults-Are-at-Risk-ofSerious-IIIness-If-Infected-with-Coronavirus.pdf 
10. Velavan T and Meyer C. The COVID-19 epidemic. Tropical Medicine and International Health. 2020; 25(3):278-280. https://doi.org/10.1111/tmi.13383

11. Vally $\mathrm{H}$. Why are older people more at risk of coronavirus? [Internet]. The Conversation. 2021 [cited 1 March 2021] Available from: https://theconversation.com/why-are-olderpeople-more-at-risk-of-coronavirus- 133770

12. Sim K. The psychological impact of SARS: a matter of heart and mind. Canadian Medical Association Journal. 2004; 170(5):811-812. https://doi.org/10.1503/cmaj.1032003

13. Holmes E, O'Connor R, Perry V, Tracey I, Wessely S, Arseneault $\mathrm{L}$, et al. Multidisciplinary research priorities for the COVID-19 pandemic: a call for action for mental health science. The Lancet Psychiatry. 2020; 7(6):547-560. https://doi.org/10.1016/s2215-0366(20)30168-1

14. Caring for Health Care Warriors Mental Health Support During COVID-19 [Internet]. Mohfw.gov.in. 2021 [cited 1 March 2021]. Available from: https://www.mohfw.gov.in/pdf/ HCWMentalHealthSupportGuidanceJuly20201.pdf

15. COVID-19 and Your Health [Internet]. Centers for Disease Contro and Prevention. 2021 [cited 1 March 2021]. Available from: https:// www.cdc.gov/coronavirus/2019-ncov/long-term-effects.html

16. Chen K, Li T, Gong F, Zhang J and Li X. Predictors of HealthRelated Quality of Life and Influencing Factors for COVID-19 Patients, a Follow-Up at One Month. Frontiers in Psychiatry.
2020; 11.

https://doi.org/10.3389/fpsyt.2020.00668

17. Name J, Souza A, Vasconcelos A, Prado P and Pereira C. Zinc, Vitamin D and Vitamin C: Perspectives for COVID-19 With a Focus on Physical Tissue Barrier Integrity. Frontiers in Nutrition. 2020; 7. https://doi.org/10.3389/fnut.2020.606398

18. Zhao J, Yang Y, Huang H, Li D, Gu D, Lu X, et al. Relationship between the ABO Blood Group and the COVID-19 Susceptibility. medRxiv 2020.03.11.20031096. https://doi.org/10.1101/2020.03.11.20031096

19. Schofield G, Beek M, Ward E and Biggart L. Professional foster carer and committed parent: role conflict and role enrichment at the interface between work and family in long-term foster care. Child \& Family Social Work. 2013; 18(1):46-56. https://doi.org/10.1111/cfs.12034

20. Cobham V, McDermott B, Haslam D and Sanders M. The Role of Parents, Parenting and the Family Environment in Children's PostDisaster Mental Health. Current Psychiatry Reports. 2016; 18(6). https://doi.org/10.1007/s11920-016-0691-4

21. Sahoo S, Mehra A, Dua D, Suri V, Malhotra P, Yaddanapudi L, et al. Psychological experience of patients admitted with SARSCoV-2 infection. Asian Journal of Psychiatry. 2020; 54:102355. https://doi.org/10.1016/j.ajp.2020.102355

\section{Author's contributions:}

KRH- Contributed to the management of the study, developed the detailed plan for analysis, supervised the running of the study, quantitative analysis and led the drafting of the article and is the guarantor for the article; PN- had the original idea for the protocol, developed the protocol, provided day-to-day overall management of the study, coordinated recruitment, follow-up, and data entry and commented on drafts of the article; LV,MV- Led the development of the protocol for ethical approval, supervised the study, and contributed to the analysis and drafting of the article; SM- Helped develop the protocol and contributed to developing the detailed plan for analysis and the drafting of the article; PS- Helped develop the protocol and contributed to developing the detailed plan for analysis and contributed to the drafting of the article.

\section{Work attributed to:}

Srinivas Hospital, SIMSRC, Mukka, Mangaluru, Karnataka, India.

\section{Orcid ID:}

Dr Kiran Raj Hanumantha- (1) https://orcid.org/0000-0002-5986-2321

Dr Pooja Naik- (1) https://orcid.org/0000-0003-0456-7955

Dr Lavanya Varma- (D) https://orcid.org/0000-0002-2642-0068

Dr Manoj Varma- (iD https://orcid.org/0000-0003-3728-4791

Dr Shruthi Manipal- (1) https://orcid.org/0000-0002-2803-8065

Dr Pavitra Sampath- (D) https://orcid.org/0000-0002-9610-1388

Source of Funding: None, Conflict of Interest: None. 